\title{
ACAMPAMENTO CHICO MENDES: NOVO PARADIGMA DE RESOLUÇÃO DE CONFLITOS.
}

\section{Shirley Silveira Andrade}

Mestre em direito-Instituto de Ensino superior de Olinda- IESO- silveiran@hotmail.com

\section{Mariana Carneiro Leão Figueiroa}

Aluna de graduação em direito- Universidade Salgado de Oliveira-marianafigueiroa@hotmail.com

RESUMO: Este trabalho tem como objeto o estudo da legitimidade das formas de resolução de conflitos internos dos integrantes do acampamento Chico Mendes na Usina Tiúma em São Lourenço da Mata, no estado de Pernambuco, sem acionar o Estado, ou se utilizando de meios que não estão expressos claramente na legislação estatal para acioná-lo, no período de maio a dezembro de 2004. Partimos da hipótese que são legítimas, a partir de um novo conceito de legitimidade: pluralismo jurídico. Nossa hipótese vem se confirmando com base nos critérios de efetividade material e formal de Antonio Carlos Wolkmer. A metodologia utilizada é a observação-participante. Onde observamos, com visitas semanais ao acampamento, formas alternativas de resolver conflitos como as instâncias de decisão, quais sejam: núcleos de família, reunião interna dos coordenadores, Assembléia Geral. Nessas instâncias são discutidos, resolvidos problemas e aplicadas sanções, como a expulsão do(a) acampado(a), ou a aplicação de tarefas laborativas que venham a beneficiar o acampamento. Além disso, acompanhamos um bloqueio de quatro horas na BR 408 como uma forma alternativa de acionar o Estado, para atender ao direito à alimentação e à vistoria das terras ocupadas. Essas são as formas de resolução de conflitos internos utilizados pelo nosso sujeito como meio de atender suas necessidades fundamentais.

PALAVRAS-CHAVE: Pluralismo Jurídico. Legitimidade. Necessidades fundamentais. 


\section{COMO ESTAMOS ESTUDANDO O ACAMPAMENTO CHICO MENDES}

A hipótese do nosso trabalho vai contra o senso comum doutrinário, este reconhece apenas um sujeito legítimo criador de Direito que é o Estado. Nas relações sociais, estão inseridos conflitos que necessitam ser encaminhados. Os teóricos liberais fortalecem a idéia do Estado como o único sujeito responsável em resolvê-los, à medida que defende a centralização política e jurídica. Contudo, o que podemos observar em nosso país é a dificuldade do exercício de direitos através desse sujeito. Apesar dessa situação, os conflitos são encaminhados pelos grupos sociais, uma vez que têm dificuldade de acesso ao poder estatal, eles resolvem seus próprios problemas. Ou utilizam-se de formas não previstas expressamente na norma estatal para ter acesso à sua jurisdição.

Diante dessas reflexões, privilegiamos estudar se as formas utilizadas pelos membros do acampamento Chico Mendes, integrantes do MST-PE, de encaminhar seus conflitos dentro do contexto acima são legítimas. Na fase a qual se encontra a pesquisa, percebemos que nossa hipótese vem sendo confirmada. A coleta de dados vem sendo feita através da observação participante com visitas semanais ao acampamento, registradas por meio de relatórios.

O acampamento Chico Mendes, objeto da pesquisa, escolhido devido à proximidade com a capital, Recife, onde residimos, compõe-se de cerca de 400 famílias que estão acampadas na Fazenda Tiúma desde 27 de Março de 2004, fazendo dele o maior acampamento do Estado de Pernambuco. Dentro desse universo, escolhemos primeiramente os líderes dos setores internos do acampamento como fonte de coleta de dados. Eles nos deram alguma direção de que reuniões ir e que pessoas conversar. Mas é bom ressaltar que interagimos tanto com os líderes como com os acampados.

Vimos que o objeto desta pesquisa, do tipo exploratório, demanda a escolha de métodos de natureza qualitativa. Os dados obtidos com a nossa pesquisa são eminentemente qualitativos, através da observação-enquanto-participante, que consiste numa nítida demarcação entre o pesquisador e seu objeto de estudo. Tratase de uma observação quase formal e um curto espaço de tempo'.

\footnotetext{
1 MINAYO, Mo Cláudia de Souza. O desafio do conhecimento: Pesquisa qualitativa em saúde. 4ํe. ed. São Paulo - Rio de Janeiro: Hucitec Abrasco, 1996. Pág. 279.
} 
A análise qualitativa nos permitiu compreender 0 modo como 0 acampamento Chico Mendes resolve seus conflitos internos sem acionar o Estado. Pois segundo a metodologia estudada, para conhecer o comportamento do grupo, o pesquisador deverá interagir em sua intimidade pois, o objetivo da pesquisa de campo é aprender o ponto de vista do nativo: sua visão de mundo e sua relação com a vida em sociedade ${ }^{2}$.

$\mathrm{Na}$ nossa chegada ao campo, observamos que o acampamento estava ainda se organizando, se estruturando como acampamento, pois era muito recente, só faziam dois meses da ocupação. A coleta de dados foi realizada através das visitas semanais feitas ao acampamento. Durante os meses de maio a novembro de 2004, fomos ao acampamento aos domingos quando ocorre a Assembléia Geral e às quintas-feiras quando há reunião do setor de formação e comunicação com os acampados. Além dessas vistas, participamos de um Bloqueio feito na BR 408 pelos acampados com o objetivo de conseguir a vinda das cestas básicas e 0 agendamento do INCRA para fazer as vistorias nas terras.

De todas as visitas foram feitos relatórios que tinham como objetivo facilitar o levantamento de dados/informações obtidos. No início, anotávamos nossas observações na frente dos acampados, mas notamos uma certa desconfiança da parte deles, talvez porque muitos são analfabetos e se sentiam ameaçados com o que podíamos estar escrevendo. Então decidimos não mais fazer anotações em público. Ao término de cada visita, no caminho de volta, relatávamos num gravador a impressão de cada um, depois as informações eram passadas para o papel. Nesta observação-como-participante, procura-se conhecer melhor o comportamento do grupo e busca descobrir quais os tipos de conflitos mais freqüentes, e como se deu à solução internamente. A pesquisa ainda está em andamento, pois estamos na fase de entrevistas.

Com essa pesquisa temos como objetivo reconhecer a existência de outras manifestações normativas informais, porém eficazes, não derivadas dos canais estatais, mas emergentes de lutas e conflitos, além de especificamente, demonstrar que as formas de resolução de conflitos usadas pelos integrantes do acampamento Chico Mendes em São Lourenço da Mata/PE são legítimas. Procuramos formular 
um novo conceito de legitimidade no sentido de aceitação: o Estado e a sociedade aceitarem esse "direito local".

O pluralismo jurídico de teor comunitário-participativo ${ }^{3}$ é um novo paradigma, pois não nega o direito estatal, mas reconhece outros sujeitos criadores de direitos. Ou seja, instrumentaliza o direito preparando-o para atender melhor os conflitos sociais e para compreender melhor as diferenças.

\section{ATUAÇÃO PLURALISTA DOS INTEGRANTES DO ACAMPAMENTO CHICO MENDES}

O censo Agropecuário de 1995-96 mostra que as propriedades de menos de 10 hectares aproveitam mais de $65 \%$ da terra para a agricultura naquele ano. Já as de mais de $1 \mathrm{mil}$ hectares utilizam apenas 5\%. Os estabelecimentos com área entre 10 e 1 mil hectares, que somam a maior área, têm um índice de 18,5\% de aproveitamento. Esses números mostram que existe muita terra ociosa no Brasil, enquanto milhões de famílias tem sua dignidade desrespeitada ${ }^{4}$.

Diante disso, os grupos sociais se organizam para enfrentar essa realidade. $O$ acampamento Chico é uma dessas ações. Iniciado em 27 de março de 2004, tem como objeto, viabilizar o acesso de várias famílias a lutarem pela sua dignidade. Ele é organizado de forma que venha descentralizar o poder dos líderes e permitir que todos os acampados participem ativamente da formação e organização do acampamento. 0 nosso sujeito possui três instâncias de decisão, quais sejam: núcleo de família, reunião interna dos coordenadores e Assembléia Geral. Elas não são claramente definidas como tal, mas as classificamos em três através das nossas análises. Não há uma hierarquia declarada entre essas instâncias, a competência de uma ou outra se dá devido à gravidade do problema, ou sua repercussão naquele meio.

No núcleo de família, que consideramos ser uma primeira instância, são encaminhados os conflitos específicos do núcleo, como a denúncia de um membro do grupo ao seu coordenador. É formado por 16 famílias, representados por um homem e uma mulher de cada família; dois coordenadores, sendo um homem e uma mulher, ficam responsáveis por tentar solucionar os problemas de seu grupo ou

\footnotetext{
${ }^{3}$ Categoria criada pelo Professor da UFSC Antonio Carlos Wolkmer.

${ }^{4}$ REVISTA MST: "A historia da luta pela terra e o MST”. São Paulo: Expressão popular, 2001. pág. 116.
} 
encaminhar para outra instância. O papel desses grupos de famílias é importante pois, cada grupo possui um dia no mês que corresponde ao seu dia de trabalho dentro do acampamento, seja para cuidar da vigilância, seja para plantar na roça coletiva, que tem o intuito de abastecer o acampamento.

$\mathrm{Na}$ reunião interna dos coordenadores, considerada como a segunda instância, são discutidos os problemas coletivos e individuais de grande relevância, além de avaliação periódica da situação do acampamento em relação ao $\operatorname{lncra}^{5}$ e a Conab $^{6}$. Nesta reunião é organizada a pauta da assembléia. Participam desta reunião, os coordenadores dos núcleos de família, coordenador geral do acampamento e eventualmente os coordenadores regionais.

A Assembléia Geral funciona como a terceira instância. São encaminhados aqueles problemas de maior repercussão e que necessitam da participação de todos os acampados para solucioná-lo, a exemplo da suspensão e expulsão de acampados, como informes sobre a negociação com Incra e outros. Acontece sempre aos domingos às $13 \mathrm{~h}$ na 'praça da bandeira', em pé, embaixo do sol quente e, via de regra, tem caráter eminentemente informativo, todavia, freqüentemente observam-se algumas deliberações. O responsável da assembléia, que pode ser qualquer coordenador, apresenta a pauta, dá os informes da semana e apresenta as pessoas que não são do acampamento.

Também na assembléia geral é feita a arrecadação de dinheiro, quando é necessário, o motivo é apresentado na própria assembléia que arrecadou e o montante é contabilizado imediatamente. Cada acampado é livre para contribuir com o que quiser e puder. A prestação de contas é feita na Assembléia seguinte.

Quanto às sanções, estas são discutidas nas instâncias de decisões. Estabelecemos também diferentes graus entre elas. A primeira delas é a falta, registrada na ausência do acampado no seu dia de trabalho coletivo, falta em assembléias, e na conduta de menor reprovação. As Tarefas educativas consistem na apresentação oral para o seu núcleo de família, de algum tema de interesse do grupo, por ter cometido um ato reprovável. Na tarefa laboral, é designado ao acampado a execução de alguma benfeitoria necessária no acampamento.

\footnotetext{
${ }^{5}$ INCRA: Instituto Nacional de Colonização e Reforma Agrária.

${ }^{6}$ CONAB: Companhia Nacional de Abastecimento.
} 
Ocorre suspensão quando, através de votação em assembléia geral, fica decidida que a presença de determinado acampado deve ser privada por um determinado tempo do grupo, por ter o mesmo cometido uma conduta como chegar bêbado e perturbando a ordem no acampamento, por exemplo. Já a expulsão, acontece na reincidência ou prática de uma conduta considerada grave ou gravíssima e que cause repulsa do grupo. É decidido em assembléia geral, e o acampado uma vez expulso não poderá retornar ao mesmo acampamento. A sanção não passa da pessoa do acampado, ou seja, tem caráter personalíssimo, logo não atinge ao seus familiares.

Os conflitos mais freqüentes observados no acampamento Chico Mendes são: pequenos furtos de bens móveis e de parte da plantação de alguns acampados; falta de alimentação que deveria ser fornecida pelo governo federal através da Conab, falta de acampado no dia de mutirão, a embriaguez, ameaça de despejo, o assédio à mulher alheia, a injúria, além da falta de assiduidade nas atividades do acampamento.

Em nossas visitas dominicais, pudemos acompanhar a votação para expulsão de dois acampados: "buchudinha" e "Seu Tonho". A primeira devido ao fato de ser a coordenadora de um setor de família, e estava desviando o dinheiro arrecadado no núcleo de família. O segundo por causa da cachaça: no acampamento não é permitido portar, consumir ou vender bebida alcoólica. $O$ mesmo havia sido chamado a atenção na reunião do seu respectivo núcleo, tendo rescindido no ato. É bom esclarecer que o cerne da questão é que, devido ao fato de estar alcoolizado, seu comportamento ameaçava a boa convivência social, pois o mesmo andava pelo acampamento com o seu facão ameaçando as pessoas.

Um ponto de bastante divergência e que foi pauta de diversas Assembléias, foi à questão dos 'cachorros' soltos no acampamento: devido a acidentes (os cachorros estavam mordendo/assustando as crianças e adultos) ficou decidido, pelo critério de votação, que as pessoas que possuíssem cachorros deveriam prender os mesmos durante o dia. Outro grande problema atrelado aos cachorros é a questão da higiene/saúde pois eles fazem suas necessidades junto da cozinha e nas roças, logo esses animais seriam uma fonte de bactérias, pondo em risco a saúde dos acampados. 
Além de assistirmos às Assembléias, também interagimos com alguns acampados aleatoriamente, sempre com o objetivo de coletar dados. Em todas as nossas visitas nós procuramos ao máximo nos aproximar do nosso objeto, fizemos as refeições com eles, bebemos da água do acampamento, tudo que pudesse expurgar o peso de ser visto como "referencial do saber", e tentar fazê-los perceber que tínhamos muito para aprender com eles: como tanta gente diferente e passando por necessidades básicas podem viver reunidas, regulando suas vidas naquele meio social.

Um dos momentos mais importantes que participamos na nossa pesquisa foi o bloqueio da BR 408, que ocorreu no dia 13 de agosto de 2004, e se deu pelo fato de não terem sido fornecidas as cestas básicas prometidas pelo Governo Federal a 23 mil famílias ligadas ao MST. O interessante é que só ficamos sabendo realmente do bloqueio poucos dias antes. Na assembléia do domingo anterior ao bloqueio, foi anunciada que haveria uma assembléia especial, que se realizou um dia antes dele. No dia, chegamos lá cerca de 7:15 da manhã. Todos estavam reunidos ao pé da bandeira que fica no centro do acampamento. Vários gritos de guerra eram entoados para estimular e emocionar as pessoas.

Arranjaram uma espécie de caixa de som com várias fotos de um candidato a vereador. É bom ressaltar que no dia anterior à manifestação, por mais que eles tivessem tentado encontrar um carro de som, não tinham conseguido nada, nem alimentação. Isso nos foi dito, pela comissão que estava organizando o bloqueio. No dia do evento, o que conseguiram foi essa caixa. Não foi possível nem alimentação. Todos os acampados ficaram as horas do bloqueio sem comida. Através dessa caixa, ainda no acampamento, várias venetas de campanha desse vereador eram tocadas. Todavia, quando saímos pela BR, a caixa só foi utilizada para entoar os hinos do MST e para propagar as mensagens.

Ficamos em lugares diferentes para termos visões diferentes do ato. Quando chegaram, as pessoas já agiram como se soubessem aonde iriam interromper. Foram colocados pneus, que vieram em um caminhão junto com a caminhada, madeira, capim e pedra. E nisso foi ateado fogo. Tudo isso pegou fogo na hora ali, pelas redondezas, menos os pneus. Em meio aos gritos de guerra, todo o tempo se falava da luta dos trabalhadores. Sempre tocando músicas do MST e o discurso utilizado era sobre as providências para a reforma agrária. 
Tentamos não participar ativamente do bloqueio, pois o nosso objetivo era observar $\mathrm{o}$ ato. Houve um momento que uma senhora me deu um pau, já que todos estavam com enxadas, estrovengas, pedaços de bambu significando seus instrumentos de trabalho. Que aceitei, mas dei um jeito de me livrar. Foi simbólico, à medida que delimitava muito bem meu papel de pesquisadora para mim. Consegui diferenciar a militante da pesquisadora e isso foi muito importante(pesquisadora Shirley). Os dirigentes pediam no microfone para que não se batessem nos carros, não usassem de violência e informando que só passariam ambulâncias. Pediam para que os motoristas tivessem paciência. Que quando o governo conversasse e resolvesse o problema eles liberariam a pista.

Não presenciamos nenhuma forma de violência dos acampados. Inclusive a relação com a polícia foi tranquila durante todo o ato. Não os presenciamos em nenhum momento falando alto, ao contrário sempre conversando e tentando negociar a passagem de alguns carros que não eram ambulâncias, mas possuíam pessoas doentes. Podia até haver provocações, como a que uma senhora chegou a dizer que eles eram um bando de vagabundos, mas não responderam. Alguns caminhoneiros e motoqueiros que estavam no engarrafamento começaram a apoiar o ato cantando os gritos de guerra do movimento.

Concluímos que a atitude dos dirigentes foi muito responsável. A relação era de tal forma pacífica que alguns manifestantes chegaram a conversar com pessoas que estavam no engarrafamento. Essa interação foi pedida pelos dirigentes. Eles diziam para conversar com as pessoas, para que elas compreendessem os motivos do ato. Até um manifestante colocou para nós que disse às pessoas que eles são obrigados a fazer esse manifesto, esse ato é por estarem passando fome. $O$ interessante é que em nenhum momento, ninguém tocou no nome do candidato a vereador.

Sempre ficamos circulando, separadas, e conversando com várias pessoas em vários pontos. Chegamos a questionar aos acampados por que que estava havendo aquele evento. Muitos disseram que foi pelo fato do Incra não fazer as vistorias, não estava viabilizando a reforma agrária e também porque não estava enviando as cestas básicas. $O$ ato seria para reivindicar isso. Um até chegou a me dizer: " não tem aquela propaganda na TV que o Brasil é de todos, pois então 
estamos lutando por ele também." (pesquisadora Shirley). O bloqueio durou cerca de quatro horas, chegamos no trevo por volta das $08 \mathrm{~h}$ e só saímos por volta das $12 \mathrm{~h}$.

Houve algumas situações complicadas. Houve um rapaz que apareceu dizendo que tinha uma consulta marcada para aquele dia e precisava passar. Isso foi discutido com alguns. Foi-Ihe permitida a passagem. Em outro momento, um carro chegou e disse que havia gente doente no carro. Sempre um grupo discutia para decidir quem poderia passar em todas as barricadas. Ambulância, não havia discussão, a barricada era aberta. Toda a parte horizontal da estrada ficou coberta de mato, árvores e pneus, mas num pequeno espaço foram colocados dois paus grandes que eram retirados quando alguém era autorizado a passar.

O MST neste dia realizou bloqueios simultâneos, iniciados às $07 \mathrm{~h}$ e finalizando por volta do meio-dia, nas Brs 232, 101 e 408. Conforme os jornais locais $^{7}$, o bloqueio da BR 408 perto do trevo no quilômetro 86, foi o que causou maior engarrafamento. No final da manhã, a pista foi liberada porque o Incra prometeu liberar em 10 dias as cestas básicas para as famílias acampadas. Em visitas posteriores ao acampamento pudemos constatar a chegada das cestas básicas. Esse ato é uma forma de resolução de conflito que não está expresso de forma clara na norma estatal. Uma vez não atendido o direito à alimentação das famílias, pelas vias formais e burocráticas, utilizam-se desse recurso como forma de efetivar esse direito estatal. É uma forma de chamar atenção do Estado e da sociedade civil para acelerar o processo de reforma agrária no nosso país.

\section{LEGITIMIDADE DAS FORMAS DE RESOLUÇÃO DE CONFLITOS DO ACAMPAMENTO CHICO MENDES}

Observam-se várias concepções teóricas acerca do direito na sociedade contemporânea. A teoria dominante é o monismo jurídico, onde seus defensores reconhecem apenas um sujeito criador do direito que é o Estado. $O$ fortalecimento da teoria monista se deu com Kelsen ${ }^{8}$, que concebe o direito como um sistema fechado, logicamente hierarquizado e posto pelo Estado.

\footnotetext{
${ }^{7}$ JORNAL:DO COMMERCIO . Recife-PE, 14 de agosto de 2004,p.

${ }^{8}$ KELSEN, Hans. Teoria Geral do Direito e do Estado. Tradução de Luís Carlos Borges. 3ed, São Paulo: Martins fontes, 1998,Pág. 34.
} 
Podemos constatar que a pretensão do direito estatal em se constituir como única forma jurídica da sociedade é excludente, isto posto, observamos que a teoria kelseniana não atende a todos os anseios dessa sociedade excluída, no sentido de não acompanhar dialeticamente as mudanças sociais e os direitos insurgentes, pois reforça a função do Direito na reprodução da sociedade capitalista.

Observa-se que a crise do monismo jurídico se dá devido ao fato do positivismo jurídico permanecer preso à legalidade formal e ao monopólio da produção normativa estatal, desconsiderando a pluralidade de novos conflitos coletivos. No Estado liberal, a igualdade é mais formal do que real ${ }^{9}$, ou seja, mesmo havendo previsão legal no direito estatal, as necessidades básicas da maioria da população não são atendidas, observamos então, uma dificuldade de exercício de direito estatal. Hoje, segundo dados recentes do IBGE, apenas $25 \%$ da população brasileira têm acesso à justiça ${ }^{10}$. Logo, a crise da legitimidade do regime jurídicoliberal da sociedade contemporânea se dá pelo perecimento do direito estatal, o que por sua vez abre espaço para o surgimento de manifestações normativas nãoestatais.

Em virtude disso, adotamos uma outra concepção teórica acerca do Direito na sociedade contemporânea, para analisar a forma de resolução de conflitos do acampamento Chico Mendes: a Teoria do pluralismo jurídico comunitário participativo do Professor Wolkmer. Ela não nega o direito estatal, mas reconhece outras formas jurídicas em uma sociedade plural. Trata-se de um projeto democrático de emancipação dos sujeitos coletivos emergentes, ou seja, os Movimentos Sociais em geral.

Para Wolkmer "além das formas jurídicas positivas e dogmaticamente instituídas, herdadas do processo de colonização, torna-se imperioso reconhecer a existência de outras manifestações normativas informais, não derivadas dos canais estatais, mas emergentes de lutas, conflitos e das flutuações de um processo histórico-social participativo e em constante reafirmação". Continua afirmando que "a proposta do pluralismo jurídico de teor comunitário-participativo para espaços

${ }^{9}$ BOBBIO, Noberto. O Futuro da democracia: defesa das regras do jogo. 5 ed. São Paulo: Paz e Terra Política, 1992. Pág. 79.

10 Idem, 01. 
institucionais periféricos passa, fundamentalmente, pela legitimidade instaurada por novos atores sociais, e pela justa satisfação de suas necessidades". ${ }^{11}$

Observamos que o Direito está inserido e é fruto das práticas sociais, o pluralismo jurídico parte do pressuposto que não precisa de autorização do Estado para se criar uma norma jurídica, ou seja, o Estado não é a única fonte criadora de normas jurídicas. Nas sociedades periféricas, como o Brasil, o pluralismo jurídico, busca satisfazer as necessidades fundamentais da população que não tem acesso ao direito estatal. A intenção da teoria consiste em definir um projeto que possibilite a mudança da sociedade em função de um novo tipo de 'sujeito histórico', o Movimento Social que em muitos casos encontra formas não tradicionais de encaminhar suas necessidades e anseios.

Uma vez que a atuação estatal não consegue satisfazer o exercício de direitos fundamentais, os grupos sociais se organizam para encaminhá-los. O acampamento Chico Mendes é um desses sujeitos. Ele se situa na Fazenda Tiúma (que pertence ao Grupo Votorantin) próxima a BR 408 no Estado de Pernambuco, na cidade de São Lourenço da Mata, com cerca de 400 famílias, em 27 de Março de 2004.

O pluralismo jurídico de teor comunitário participativo busca criar alternativas que implementem práticas democráticas e participativas na elaboração de normas jurídicas, tendo como objetivo atender às necessidades fundamentais da população excluída, seja pelas vias estatais ou não, ou seja, se o direito estatal responde a demanda levando em conta as necessidades daquele grupo social, isso seria satisfatório. Caso contrário, é facultada a criação de uma norma jurídica extra-estatal que vise atender às necessidades fundamentais daquele grupo social específico. $O$ mais importante não é silogismo formal, mas encontrar o melhor meio de encaminhar conflito. $O$ meio que traga maiores benéficos à coletividade.

Não é toda norma jurídica extra-estatal que tem validade. Para Wolkmer, para que uma norma extra-estatal seja considerada jurídica e tenha validade, ela deve preencher dois tipos de efetividade: a efetividade formal e a material. Nossa hipótese está sendo confirmada com base nos critérios de legitimidade de Wolkmer,

\footnotetext{
${ }^{11}$ WOLKMER, Antônio Carlos. O Pluralismo jurídico: Fundamentos de uma nova cultura no Direito. São Paulo: Alfa-omega, 1994. Pág. 100.
} 
já que a organização e atuação dos integrantes do acampamento Chico Mendes é efetiva tanto do ponto de vista forma quanto material ${ }^{12}$.

$\mathrm{Na}$ efetividade material, devem ser observados o sujeito elaborador das normas e o conteúdo dessas normas. Quanto aos sujeitos, Wolkmer reconhece os Movimentos sociais em geral como fonte não-estatal geradora de direitos comunitários autônomos. Ele não define 'movimento social em geral', apenas delimita, dizendo que os sujeitos legítimos para elaboração de norma jurídica extraestatal, devem ser coletivos, com participação política (devem se opor a todas as formas de alienação que transformam o homem de sujeito em objeto), além de serem mais ou menos institucionalizados, ou seja, com um grau mínimo de organização.

Observamos que o nosso sujeito, os integrantes do acampamento Chico Mendes, preenchem os requisitos que fazem dele um sujeito legítimo. Trata-se de um sujeito coletivo, com participação política, já que há uma luta pro efetivação de direitos e é mais ou menos institucionalizado à medida que há uma organização de atuação e decisão. Como vimos no tópico anterior, pudemos observar com profundidade a atuação dos integrantes nas instância de decisão. Onde há os núcleos de família, a reunião dos coordenadores de núcleo e a assembléia geral.

Quanto ao conteúdo da norma, este deve ter como objetivo o atendimento das necessidades fundamentais, quais sejam: saúde, alimentação, moradia, educação, etc. Observamos também que o nosso sujeito busca exatamente satisfazer suas necessidades fundamentais. A luta é por uma vida digna com pleito a educação, saúde, terra, por cidadania.

$\mathrm{Na}$ efetividade formal, Wolkmer, estabelece quais os procedimentos para a elaboração das normas. Elas devem ser criadas a partir de discussões coletivas onde as pessoas tenham a oportunidade de se expressar. Devem ser criados mecanismos que garantam a participação de todos no grupo. A efetividade formal se confirma no nosso sujeito através da Assembléia Geral aos Domingos, onde todos os acampados tem direito a voto e a fazer uso da palavra, além das reuniões dos núcleos de família e do setor de formação e comunicação, nas quais a participação dos acampados se faz presente.

\footnotetext{
12 Idem, 14.
} 
Gostaríamos de ressaltar que ainda há uma dificuldade nessa participação, não só devido a falta de costume dessa população de participação, como às vezes alguns líderes a inibe, não só não a permitindo, como causando um certo medo de manifestação. Alguns dirigentes não sabem ainda lidar com espaços democráticos e querem impor suas idéias. Mas não há de se negar que não são em todas as instâncias que isso ocorre, e nem todas as vezes. No geral, há espaço para manifestações e decisões. Acompanhamos certa vez a discussão em uma assembléia sobre a possibilidade de expulsão de um acampado. E ele teve a oportunidade de se defender do que foi acusado. No final, depois da votação, os acampados decidiram que ele iria permanecer, a maioria decidiu isso. E não há de esquecermos que não temos uma tradição democrática. O Brasil teve grande parte de sua história formada pelo império e por repúblicas ditatoriais. Através dessas oportunidades é que vão criando as bases para uma prática democrática.

\section{CONCLUSÃO}

A partir das considerações tecidas acerca do nosso objeto, constatamos que o nosso trabalho é de suma importância, no que tange à relação entre sociedade, direito e Estado. Pois vem a contribuir com o estímulo a análise de outras formas e fontes de produção jurídica. O Pluralismo Jurídico, tema escolhido no nosso trabalho, vai contra o senso comum doutrinário dominante, onde prevalece 0 entendimento que fora do direito positivo estatal não existe direito.

O monismo jurídico não reconhece outras manifestações jurídicas senão aquelas oriundas dos canais estatais. Ao monopolizar a produção normativa no poder estatal, o positivismo jurídico, por vezes, não consegue solucionar os problemas, podendo até mesmo agravá-los. Assim, esse modelo fechado não acompanha a dinâmica da sociedade. Adotamos a teoria do pluralismo jurídico comunitário-participativo, como forma de tentar responder os problemas levantados na pesquisa.

Mesmo havendo legislação que preveja os direitos fundamentais, não se pode dizer que a Constituição Federal de 1988 inibe o exercício desses direitos, mas que o direito positivo não significa a viabilização do atendimento às necessidades 
fundamentais. Acreditamos que a interação das normas elaboradas pela sociedade e as oriundas dos canais estatais podem vir a encaminhar esse problema.

Os integrantes do Chico Mendes são um sujeito coletivo, autônomo e legítimo para elaboração de normas jurídicas extra-estatais, dentro dos critérios de efetividade acima enumerados, pois visam o atendimento de suas necessidades fundamentais, quais sejam: moradia, alimentação, saúde e educação. Uma vida digna.

Não podemos defender, no Brasil, um pluralismo que negue a importância do Estado, pois é justamente pela ausência desse sujeito, que o pluralismo se mostra como um meio essencial. Ou seja, o pluralismo jurídico, defendido por nós, é, também, um meio extra-estatal de exercício de direito estatal. Já que o nosso país possui uma legislação constitucional que busca o respeito da dignidade.

\section{REFERÊNCIAS BIBLIOGRÁFICAS}

ANDRADE, Shirley Silveira. O Movimento Popular como Sujeito Criador de Direito - Dissertação de mestrado na UFPE (30 de agosto de 2003).

BARRETTO, Nelson Ramos. Reforma Agrária: o mito e a realidade. 2ª ed. São Paulo: Artpress, 2003. BOBBIO, Noberto. O futuro da democracia: a defesa das regras do jogo. 5ำ ed. São Paulo: Paz e Terra Política, 1992.

CARDOSO, Ruth C. L. A aventura antropológica: teoria e pesquisa. Rio de Janeiro: Paz e Terra, 1997.

FALCÃO, Joaquim de Arruda. Conflito de Direito e Propriedade - invasões urbanas. Rio de Janeiro: Forense, 1984.

GRAZIANO, José da Silva. O que é questão agrária. 15ํㅗㄹ ed. São Paulo: Brasiliense, 1989.

GUIMARÃES, A. Z. (Org.) Desvendando máscaras sociais. $2^{\mathrm{a}}$ ed. Rio de Janeiro, ed. Francisco Alves, 1980 ,

JORNAL: Jornal do Comércio. Recife-PE, 14 de agosto de 2004. Caderno "Cidades".

JORNAL: Diário de Pernambuco. Recife-PE, 11 de outubro de 2004. № 285.

JORNAL: Diário de Pernambuco. Recife-PE, 12 de outubro de 2004. № 286

KELSEN, Hans. Teoria Geral do Direito e do Estado. Tradução de Luís Carlos Borges. 3ed, São Paulo: Martins fontes, 1998. 
KLIKSBERG, Bernardo. Pensando o Estado para o desenvolvimento social: Superando dogmas e convencionalismos. (Trad. Joaquim Ozório Pires da Silva). São Paulo: Cortez, 1998.

MALINOWSKI, Bronislaw. Objetivo, método e alcance desta pesquisa. IN: desvendando máscaras sociais. Organizado por Alba Zaluar Guimarães. 3를 ed, Rio de Janeiro: Livraria Francisco Alves, 1990. MINAYO, Mo Cláudia de Souza. O desafio do conhecimento: Pesquisa qualitativa em saúde. $4^{\circ}$ ed. São Paulo - Rio de Janeiro: Hucitec Abrasco, 1996.

,(Org.). Pesquisa Social: teoria, método e criatividade. 10ª ed.Petrópolis: Ed. Vozes, 1998.

OLIVEIRA, Luciano. Ilegalidade e Direito alternativo: Notas para evitar alguns equívocos. Conselho Federal da OAB - Brasília, 1996.

PÊPE, Albano Marcos Bastos e Luiz Alberto Warant. Filosofia do Direito: Uma introdução Critica. São Paulo: Moderna, 1996.

REVISTA Carta Capital: "Reforma Agrária a hora da verdade". Ano x: 25 novembro 2003.

REVISTA da OAB-PE: "Direito alternativo ou formas alternativas de Direito". Ano 32: 1997.

REVISTA MST: "A historia da luta pela terra e o MST". São Paulo: Expressão popular, 2001.

SANTOS, Boaventura de Souza. O discurso e o poder: Ensaio sobre a sociologia da retórica jurídica. Porto Alegre: Fabris, 1988.

WOLKMER, Antônio Carlos. Introdução do pensamento jurídico crítico. 4ํe․ edão Paulo: Saraiva, 2002.

.O Pluralismo jurídico: Fundamentos de uma nova cultura no Direito. São Paulo: Alfaomega, 1994. 